\title{
Effects of short chain fatty acids on a new human colon carcinoma cell line (LIM1215)
}

\author{
R H WHITEHEAD, G P YOUNG, AND P S BHATHAL
}

From the Melbourne Tumour Biology Branch, Ludwig Institute for Cancer Research, PO Royal Melbourne Hospital, Melbourne; University of Anatomical Pathology, The Royal Melbourne Hospital, Victoria, Australia

SUMmARY The effects of short chain fatty acids on a colon carcinoma cell line, LIM1215, have been studied. Of the four short chain fatty acids tested only butyrate at $1 \mathrm{mmol} / \mathrm{l}$ and $10 \mathrm{mmol} / \mathrm{l}$ and acetate at $10 \mathrm{mmol} / \mathrm{l}$ had significant effects on this cell line. The addition of butyrate to growth medium affected the growth rate and the production of alkaline phosphatase, dipeptidyl peptidase IV and carcinoembryonic antigen. Butyrate at a final concentration of $1 \mathrm{mmol} / \mathrm{l}$ increased the doubling time of the cells from 26 hours to 72 hours and decreased the cloning efficiency of the cells from $1 \cdot 1 \%$ to $0 \cdot 054 \%$. Alkaline phosphatase concentrations increased rapidly in cells cultured in $1 \mathrm{mmol} / \mathrm{l}$ butyrate reaching peak levels after four days with alkaline phosphatase concentrations increasing more than six-fold. Levels of dipeptidyl peptidase IV and carcinoembryonic antigen were also increased after culture in butyrate containing medium. The number of alkaline phosphatase containing and dipeptidyl peptidase IV containing cells increased markedly in butyrate containing cultures. In contrast the number of mucus containing cells decreased in cultures grown in medium containing butyrate. This differentiating effect of butyrate on colon carcinoma cells may be relevant to the presence of butyrate in the colonic contents and the relationship between short chain fatty acids and fibre intake.

We have recently established a new colon carcinoma cell line with the capacity to spontaneously differentiate to some degree.' Electron microscopic studies show the presence of two cell types, one with organised areas of microvilli and the other with mucin inclusions. ${ }^{1}$ In view of the presence of a range of fatty acids in the colonic lumen, this study has set out to test the effects of various short and medium chain fatty acids on the growth and differentiation of this cell line. Cellular differentiation has been followed by monitoring alkaline phosphatase, dipeptidyl peptidase IV, carcinoembryonic antigen concentrations and mucin staining.

Sodium butyrate has been shown to induce differentiation in various cell types in vitro - for example, colon carcinoma, ${ }^{2}$ Syrian hamster cells ${ }^{3}$ and erythroleukaemia cells. ${ }^{+5}$ The effect of butyrate in vivo is unknown as it is not feasible to administer

Address for correspondence: Dr R H Whitehead, Cell Biology Laboratory Ludwig Institute for Cancer Research, Royal Melbourne Hospital. Victoria 3050. Australia.

Received for publication 22 April 1986 butyrate systemically because it and other short chain fatty acids such as acetate and propionate are rapidly cleared from the circulation. ${ }^{6}$ The effects of acetate or propionate on cell differentiation is uncertain. Butyrate, acetate, and propionate are normally present in the lumen of the large bowel; ${ }^{6}$ an important consideration as the large bowel is a common site of cancer. These three short chain fatty acids comprise the major solute fraction of faecal water $\left(190 \mathrm{mmol} / \mathrm{l}^{6}\right)$ being produced by fermentation of malabsorbed or non-absorbed dietary carbohydrates - for example, fibre, by anaerobic bacteria normally resident in the large bowel. ${ }^{6}$ These short chain fatty acids are readily taken up by colonic mucosa and are preferred to glutamine and glucose as respiratory fuels for the colonocyte. ${ }^{7}$ In this natural setting, short chain fatty acids have the potential to modify growth of colonic neoplasms and perhaps even to protect against their genesis. The modulation of cell differentiation by means such as these has potential in the management and prevention of colon carcinoma, because the amounts of 
short chain fatty acids in the colon can be modified by dietary means.

\section{Methods}

CELL I.INE

The LIM1215 cell line has been described in full elsewhere. ${ }^{1}$ In brief, the cell line was obtained from a 34 year old man with a family history of colorectal cancer. His father and two brothers had previously developed colorectal cancer. At laparotomy, the patient was found to have widespread abdominal metastases and the primary lesion in the ascending colon was judged to be inoperable. The cell line was derived from tissue taken from involved omentum. ${ }^{1}$ Cells were maintained in RPMI 1640 medium supplemented with $10 \%$ fetal calf serum, $100 \mathrm{nmol} / \mathrm{l}$ insulin, $2 \mu \mathrm{mol} / \mathrm{l}$ hydrocortisone, 10 $\mu \mathrm{mol} / \mathrm{l} \alpha$-thioglycerol, $50 \mathrm{U} / \mathrm{ml}$ penicillin and 50 $\mu \mathrm{g} / \mathrm{ml}$ streptomycin as described previously. ${ }^{8}$ The cells were passaged by trypsinising with a solution of $0.1 \%$ trypsin and $0.05 \mathrm{mmol} / \mathrm{l}$ ethylene diamine tetraacetic acid (EDTA) in phosphate buffered saline $(\mathrm{pH} \mathrm{7 \cdot 2)}$.

\section{GROWTH STUDIES}

All growth studies were done in the growth medium described above. Cells were trypsinised and resuspended in medium at a concentration of $10^{5}$ cells $/ \mathrm{ml}$. One millilitre aliquots of the cell suspension were then dispersed into each well of 24 well plates (Nunc, Denmark). Appropriate dilutions of aqueous solutions of short chain fatty acids [all fatty acids tested were obtained from Sigma Chemical Co, St Louis, Mo] were then added to triplicate wells and the plates incubated at $37^{\circ} \mathrm{C}$ in an atmosphere of $5 \% \mathrm{CO}_{2}$ in air for up to seven days.

After incubation, the medium from each well was removed and stored in numbered tubes. One millilitre trypsin-EDTA solution was added to each well and the plate incubated until all cells had been detached from the growth surface. The cell suspension in each well was then added to the corresponding medium and the total cell count per well determined using a haemocytometer. Viability was determined by dye exclusion.

\section{CI.ONING STUDIES}

Monolayer cultures were trypsinised and the cells suspended in growth medium. The suspension was filtered through sterile nylon gauze $(50 \mu \mathrm{mesh})$ and then through sterile cotton wool to remove clumps and the resulting cell suspension checked for clumps by microscopy. The cell suspension was then counted using a haemocytometer and the cell count adjusted to give cell concentrations ranging from $10^{2} / \mathrm{ml}$ to $10 \% / \mathrm{ml}$ and plated in duplicate in $2 \mathrm{ml}$ volumes in $35 \mathrm{~mm}$ dishes. The colonies formed were counted at 10 days. Aggregates of more than 50 densely packed cells were counted as colonies.

ALKAIINE PHOSPHATASE

Cells $(2 \times 10 \% / \mathrm{ml})$ were grown in flasks in media containing short chain fatty acids. After incubation, the culture medium was collected and stored. The cell monolayer was then rinsed twice in $10 \mathrm{mmol} / \mathrm{l}$ Tris $\mathrm{HCl}$ buffer, $\mathrm{pH} 7 \cdot 4$, containing $250 \mathrm{mmol} / \mathrm{l}$ mannitol buffer and in the same buffer containing 5() $\mathrm{mmol} / \mathrm{l}$ mannitol. Trypsin was not used.

The cells were removed by scraping in ice cold 50 $\mathrm{mmol} / \mathrm{l}$ mannitol buffer, centrifuged and the cell pellet stored at $-20^{\circ} \mathrm{C}$ until assayed. Immediately before assay, the cell pellet was homogenised for 15 seconds using a size $\mathrm{C}$ tissue grinder (A H Thomas, Philadelphia, PA) with a Teflon pestle rotating at full speed. For alkaline phosphatase and protein assays, aliquots of homogenate were made up to $0.1 \%$ Triton X-100 (Sigma Chemical Co, St Louis) before assay. Determination of alkaline phosphatase activity was carried out with p-nitrophenyl phosphate as substrate according to the method previously described $^{9}$ using a 2-amino-2-methylpropanol (Sigma) buffer. Protein was measured with bovine gamma-globulin as standard. ${ }^{10}$ All determinations were made in duplicate or triplicate.

\section{CARCINOEMBRYONIC ANTIGEN}

Carcinoembryonic antigen (CEA) was measured using a solid phase radioimmunoassay kit (Abbot CEA-RIA Diagnostic kit no. 7875, Abbot Laboratories, North Chicago). Carcinoembryonic antigen release into culture media was measured by direct assay of media diluted in CEA extraction buffer. Membrane bound CEA was measured in homogenates prepared as above, solubilised by $1 \%$ NonidetP40 (BDH Chemical Ltd, Poole, England) at $4^{\circ} \mathrm{C}$ for 30 minutes and then centrifuged at low speed (5000 $\mathrm{g}$ for 10 minutes) to collect solubilised material. [Triton X-100 did not achieve adequate solubilisation of CEA.] Carcinoembryonic antigen concentrations were expressed as $\mathrm{ngm} / \mathrm{mg}$ cell protein.

SCANNING ELECTRON MICROSCOPY STUDIES

For scanning electron microscopy, the cells were grown for five days on plastic coverslips (Thermanox, Lux Scientific Corp, Newbury Park, CA), washed briefly in PBS, fixed in $2.5 \%$ glutaraldehyde in $0.1 \mathrm{M}$ cacodylate buffer for 30 minutes, washed in three changes of cacodylate buffer containing ().25 $\mathrm{mol} / \mathrm{l}$ sucrose, postfixed in $2 \%$ osmium tetroxide for 
one hour, washed again with buffer, dehydrated through a graded series of ethanol and dried by the critical point method using liquid carbon dioxide as the infiltrating medium. The coverslips were then mounted on stubs, shadow-coated with gold and viewed in an Etec Autoscan at $20 \mathrm{kV}$.

DIPEPTIDYL PEPTIDASE IV (DPPIV)

This enzyme was assayed using glycyl-L-proline-pnitroanilidine as substrate as described by Nagatsu $e t$ al. ${ }^{11}$

IMMUNOCHEMICAL STAINING

LIM1215 cells were grown on 8-chamber Lab Tek slides (Miles Laboratories Inc, Naperville, USA) for five days either in control medium or in medium containing $1 \mathrm{mmol} / \mathrm{l}$ sodium butyrate. After five days, the slides were washed in phosphate buffered saline, fixed in acetone at $-20^{\circ} \mathrm{C}$ for 10 minutes and air dried. Alkaline phosphatase activity was demonstrated histochemically using the Napthol AS-BI (Sigma) method. ${ }^{12}$ Mucus was demonstrated using two monoclonal antibodies raised against either human colonic mucosal membranes (MONO24, Gardner I, in preparation) or purified colonic mucous (LIMA, kindly supplied by $\mathbf{J}$ Ma, Monash University Melbourne). ${ }^{13}$ Dipeptidyl peptidase IV (DPPIV) was demonstrated using a monoclonal antibody kindly supplied by Dr H-P Hauri, Basel, Switzerland. ${ }^{14}$

\section{STATISTICAL ANALYSIS}

All statistical comparisons were made using the Wilcoxon's rank sum test.

\section{Results}

\section{GROWTH STUDIES}

The effects of fatty acids at a range in concentrations on the growth of LIM1215 cells in monolayer culture are summarised in Table 1, where growth is expressed as a percentage of control growth. Three of the short chain fatty acids tested were tested at three concentrations and of these only propionate at $10 \mathrm{mmol} / \mathrm{l}$ and butyrate at $1.0 \mathrm{mmol} / \mathrm{l}$ and $10 \mathrm{mmol} / \mathrm{l}$ significantly suppressed growth $(\mathrm{p}<0 \cdot 05)$. Valerate and isovalerate were only tested at a single concentration $(1 \mathrm{mmol} / \mathrm{l})$ but neither suppressed the growth of LIM1215 cells at this concentration (results not shown). There was no significant stimulation of growth with any of the fatty acids tested.

Because of its effects, butyrate was studied further. Growth curve studies (Fig. 1) indicated that $1 \mathrm{mmol} / \mathrm{l}$ butyrate increased the doubling time from 26 hours in control cultures to 72 hours in butyrate treated cultures. The total cell yield was also
Table 1 Growth of LIMI215 cells in the presence of short chain fatty acids

\begin{tabular}{|c|c|c|}
\hline & & (ells per well $\left(\times 10^{\circ}\right)(n)$ \\
\hline - - - & - & \\
\hline \multirow{3}{*}{ Acetate } & (). $1 \mathrm{mmol} / \mathrm{l}$ & $8.7 \pm(1) .8$ \\
\hline & $1.0 \mathrm{mmol} / \mathrm{l}$ & $7 \cdot 4 \pm 1 \cdot 1$ \\
\hline & 10.() $\mathrm{mmol} / \mathrm{l}$ & $5.9 \pm 0.5$ \\
\hline \multirow{3}{*}{ Propionate } & (1). $1 \mathrm{mmol} / \mathrm{l}$ & $7 \cdot 5 \pm 1 \cdot 3$ \\
\hline & $1.0 \mathrm{mmol} / \mathrm{l}$ & $6 \cdot 8 \pm(1) \cdot 3$ \\
\hline & $10 .(1) \mathrm{mmol} / \mathrm{l}$ & $1 \cdot 3 \pm 01.2 \dagger$ \\
\hline \multirow[t]{3}{*}{ Butyrate } & (0. $1 \mathrm{mmol} / \mathrm{l}$ & $6.8 \pm 1.4$ \\
\hline & $1.0 \mathrm{mmol} / \mathrm{l}$ & $2 \cdot() \pm(0.2 \dagger$ \\
\hline & $10.0 \mathrm{mmol} / \mathrm{l}$ & $1 \cdot 4 \pm(1) \cdot 1 \div$ \\
\hline Control & & $8 \cdot 1 \pm 1 \cdot 2$ \\
\hline
\end{tabular}

${ }^{*}$ Mean of three cultures \pm 1 standard deviation, †Significant reduction in growth $(p<0) \cdot(15)$.

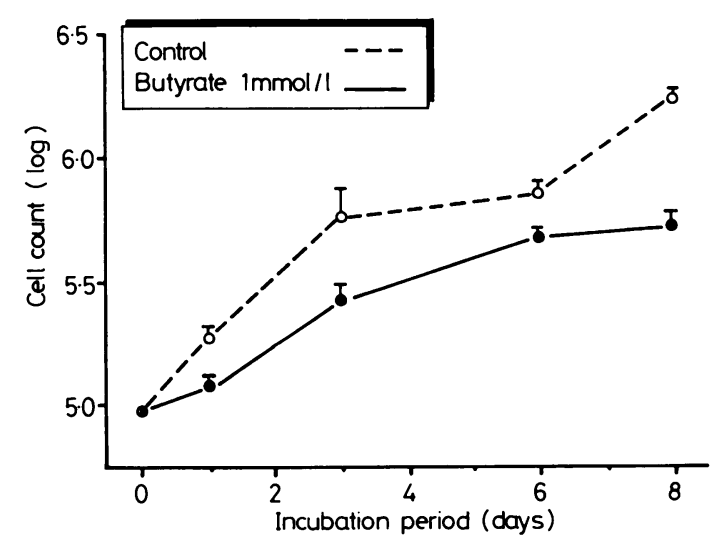

Fig. 1 Growth of LIM1215 cells in either control or butyrate-containing (I mmolll) media. SEM indicated by vertical bars. $(N=3$ for each data point).

decreased. This effect was not caused by toxicity, however, as the viability of the cells was not affected and dead cells were not shed into the medium.

Growth in butyrate containing medium also induced a change in the morphology of the cells. The cells became much larger and flatter within two to three days of the addition of butyrate to the culture. This was shown by demonstrating an increase in low angle scatter (a parameter related to cell size) using a cytofluorograph. The mean channel for low angle scatter for control cells was 73 and this increased to 95 for cells grown in butyrate containing medium for 5 days.

\section{CLONING EFFICIENCY}

LIM1215 cells were cloned at low cell density in 
liquid culture either in control medium or medium containing $1 \mathrm{mmol} / \mathrm{l}$ sodium butyrate. In control cultures, $11 \pm 1$ colonies were obtained with an inoculum of $10^{3}$ cells $/ \mathrm{ml}$ giving a cloning efficiency of $1 \cdot 1 \%$. In contrast, in butyrate containing cultures, $5 \pm 3$ colonies were obtained with a cell inoculum of $10^{4} / \mathrm{ml}$ giving a cloning efficiency of $0.05 \%$ and maximal cloning was only obtained at an inoculum of $10^{5}$ cells $/ \mathrm{ml}$.

\section{ALKALINE PHOSPHATASE}

Alkaline phosphatase specific activity was significantly increased $(p<0.05)$ by the addition of acetate $(1.0 \mathrm{mmol} / \mathrm{l}$ and $10.0 \mathrm{mmol} / \mathrm{l})$, propionate $(1.0$ $\mathrm{mmol} / \mathrm{l})$ and most markedly by butyrate at a concentration of $1.0 \mathrm{mmol} / \mathrm{l}$ (Fig. 2). The effects of various concentrations of butyrate on cell growth and alkaline phosphatase specific activity are shown in Figure 3. A concentration of $1 \mathrm{mmol} / \mathrm{l}$ significantly $(\mathrm{p}<0.02)$ suppressed growth and was associated with a marked increase $(p<0.02)$ in alkaline phosphatase activity. Figure 4 shows that the butyrate induced increase in alkaline phosphatase specific activity appeared within 24 hours but plateaued at three to four days. The increase had become significant by day two $(p<0 \cdot 02)$. In contrast, total activity continued to increase progressively relative to controls (Fig. 5).

\section{ULTRASTRUCTURE STUDIES}

Scanning electron microscope studies have confirmed the morphological observations on changes in cell size in butyrate containing medium. Interestingly, the distribution and number of microvilli did

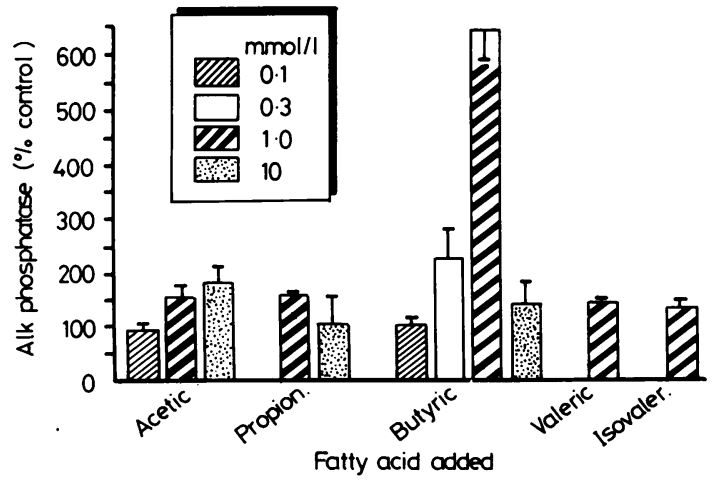

Fig. 2 Influence of various short chain fatty acids on alkaline phosphatase activity. Fatty acids added were acetic, propionic (propion), butyric, valeric and isovaleric (isovaler). Cultures were maintained for five days before the enzyme was assayed. SEM indicated by vertical bars. $(n=3)$

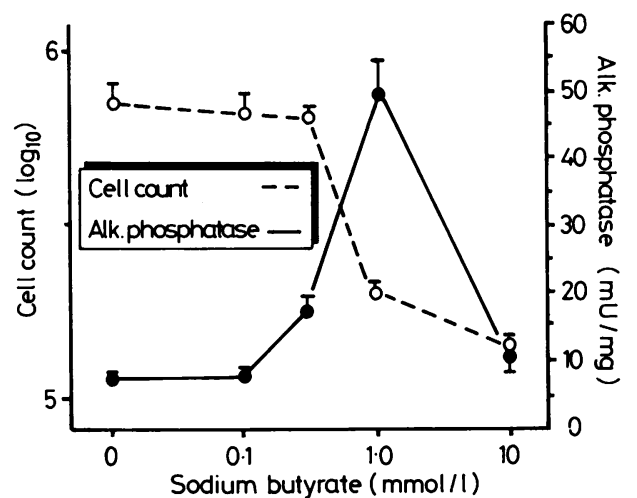

Fig. 3 Efect of various concentrations of butyrate on cell growth and alkaline phosphatase activity. SEM indicated by vertical bars. $(n=3)$

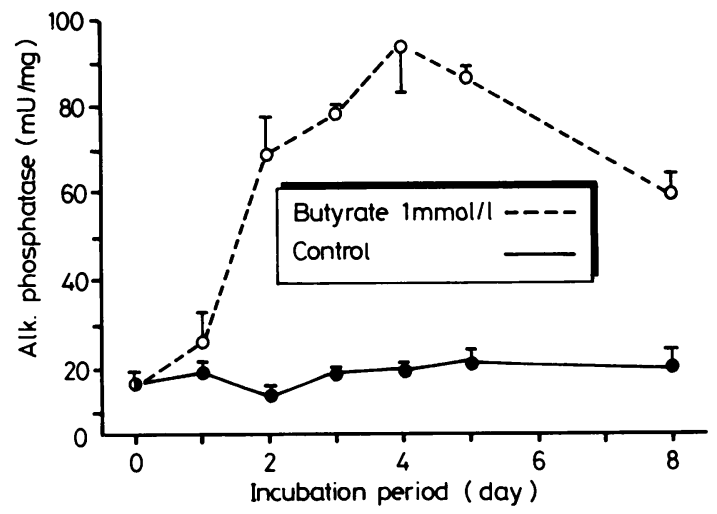

Fig. 4 Time course of induction of alkaline phosphatase activity ( $\mathrm{mU} / \mathrm{mg}$ cell protein) when cultured in I mmol/l butyrate. SEM indicated by vertical bars. $(n=3)$

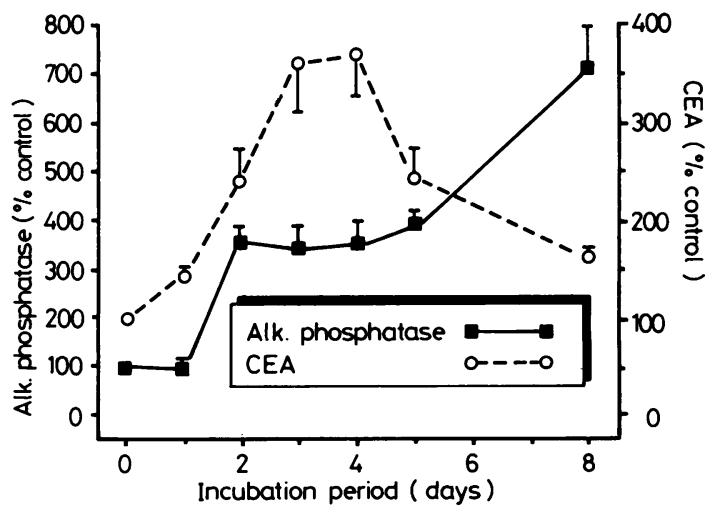

Fig. 5 Time course of total alkaline phosphatase activity and carcinoembryonic antigen per culture, when cultured in 1 mmolll butyrate. SEM indicated by vertical bars. $(n=3)$ 
not appear to be altered by growth in butyrate containing medium (Figs 6a and 6b).

\section{CEA PRODUCTION}

Monolayers cultured in the presence of butyrate produced significantly more CEA than did control cultures. Carcinoembryonic antigen production continued to increase with length of exposure, although
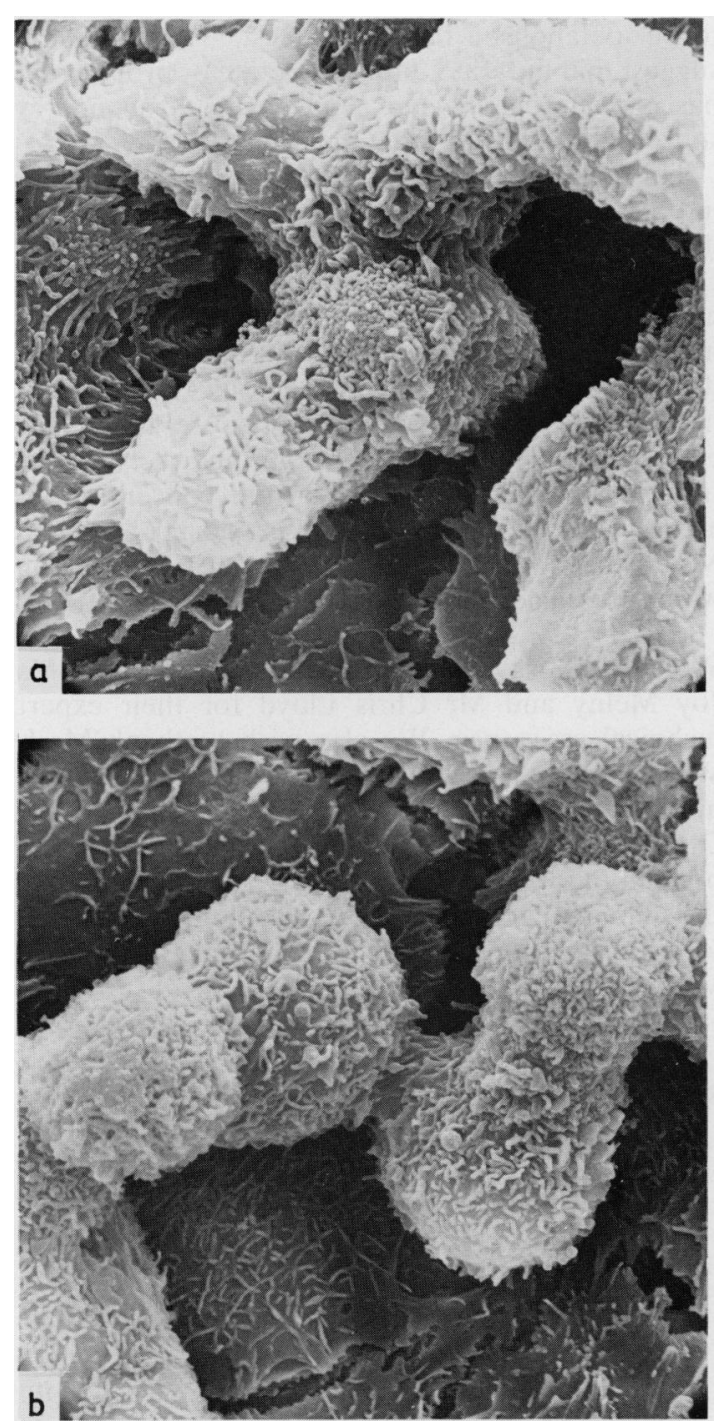

Fig. 6 Scanning electron micrographs of: (a) culture grown in control medium; and (b) cultures grown in medium containing 1 mmolll butyrate. Both cultures were grown for five days before processing. There were no differences in either the density or the distribution of microvilli.
Table 2 Effects of 1 mmol/l butyrate on antigen expression by LIMI215 cells in monolayer culture

\begin{tabular}{lcc}
\hline & Control & Butyrute (I mmolll) \\
\hline Alkaline phosphatase & $1 \%{ }^{*} \pm+$ & $30 \%+$ \\
DPPIV & $3 \%+$ & $60 \%+$ \\
Mucus - Mono24 & $25 \%+$ & $5 \% \pm$ \\
LIMA & $20 \%++$ & $10 \%+$ \\
\hline
\end{tabular}

* Percentage of cells positive in five day cultures. IIntensity assessed on a scale varying from $\pm=$ barcly discernable to $\ddagger=$ extremely strong.

not as rapidly as for alkaline phosphatase (Fig. 5). Total CEA production per culture flask increased three to four-fold $(p<0.05)$ during the first four days of culture (Fig. 5), but then fell back towards control values. In contrast, alkaline phosphatase concentrations continued to rise.

\section{DIPEPTIDYLAMINOPEPTIDASE}

Butyrate, $1 \mathrm{mmol} / \mathrm{l}$, increased activity of this enzyme approximately $35 \%$ from $4.58 \pm 0.49 \mathrm{mU} / \mathrm{mg}$ protein $(\bar{x} \pm S E)$ in control media to $6.30 \pm 1.25 \mathrm{mU} / \mathrm{mg}$ in butyrate containing media, after five days of culture.

\section{HISTOCHEMICAL STUDIES}

The percentage of cells expressing alkaline phosphatase activity or containing dipeptidyl peptidase IV was increased markedly by culture in $1 \mathrm{mmol} / \mathrm{l}$ butyrate (Table 2). The intensity of the histochemical reaction for alkaline phosphatase was also increased. In contrast, the percentage of cells in the culture staining with antimucus antibodies decreased in butyrate cultures (Table 2 ).

\section{Discussion}

Butyrate is a potent differentiating agent in many systems. ${ }^{3} 15$ 16 It has been widely studied in a murine erythroleukaemia system ${ }^{17-19}$ and has been shown to induce granulocyte differentiation in human promyelocytic leukaemia cells. ${ }^{20}$ Butyrate also has differentiating effects on human retinoblastoma cells in monolayer culture ${ }^{21}$ and on antigen production by the human breast carcinoma cell line MCF$7 . .^{5}$ Although the mode of action of butyrate is still unclear, it is known that butyrate alters histone acetylation patterns by reducing nuclear histone acetyltransferase and inhibiting histone deactylase. ${ }^{1622}$ Butyrate also inhibits phosphorylation of histones and can interfere with methylation of nuclear protein fractions. ${ }^{12} 2.3$ Although butyrate has been studied in many systems it is of interest in relation to the colon as it is present in high concentration in colonic contents. ${ }^{6}$ Other short 
chain fatty acids are also present in colonic contents ${ }^{6}$ but these have received little attention in previous studies.

In this study, we have investigated the effects of a range of short chain fatty acids on a new human colon carcinoma cell line (LIM1215). ${ }^{1}$ It has previously been shown by Kim and his coworkers that butyrate increases the concentrations of alkaline phosphatase and CEA in other cell lines derived from colonic and rectal carcinomas. ${ }^{22-26}$

Butyrate induced various characteristics of differentiation in LIM 1215 cells. The doubling time of the cells was increased markedly and the cloning efficiency was decreased. Both the number of cells producing alkaline phosphatase and the total amount of alkaline phosphatase being produced increased markedly. Concentrations of CEA increased for three to four days after exposure to butyrate, but the rise was not as sustained as for alkaline phosphatase. Carcinoembryonic antigen concentrations may be much higher in colonic tumours than in normal colon, but paradoxically, in tissue culture studies CEA concentrations are higher in tumour cell lines which are well differentiated than in lines derived from poorly differentiated or anaplastic tumours as previously shown by Shi et al. ${ }^{25}$ Butyrate also induced dipeptidyl peptidase activity in this cell line in a similar manner to that previously observed in other colon carcinoma cell lines by Chung et al. ${ }^{27}$ Although the increase in the total level of the enzyme was only $35 \%$ which is modest when compared with the $600 \%$ increase in alkaline phosphatase, the number of cells with detectable concentrations of DPPIV increased from $3 \%-60 \%$ using immunofluorescence. The effects of butyrate on the levels of alkaline phosphatase, dipeptidyl peptidase and CEA indicates that butyrate has effects on the expression of a number of membrane glycoproteins, although these effects vary in degree. Although the mechanism of action of butyrate in inducing these changes in this cell line are unknown, the scanning electron microscopy study has shown that the increase in concentrations of alkaline phosphtase and dipeptidyl peptidase is not simply because of an increase in the number of microvilli on the surface of these cells (Figs 6a and $b$ ).

We have previously shown that cultures of LIM1215 cells contain two morphologically distinct cell types, one with microvilli on the surface and the other containing mucous inclusions in the cytoplasm. ${ }^{11}$ These findings suggest that LIM1215 cultures contain multipotent cells capable of differentiating along either the absorptive cell pathway or the goblet cell pathway. ${ }^{1}$ The fact that butyrate increased the number of alkaline phosphatase con- taining and DPPIV containing cells and decreased the number of mucous producing cells (Table 2) suggests that butyrate is causing the LIM1215 cells to differentiate along the absorptive cell pathway.

In contrast to the effects of butyrate, the other short chain fatty acids tested, acetate, propionate, valerate or isovalerate, had little differentiating effects on LIM1215 cells. This finding is of interest as acetate and propionate occur in the colon at higher levels than butyrate ${ }^{6}$ and all three are known to be metabolised by enterocytes. ${ }^{7}$ These findings suggest that butyrate, but not acetate or propionate, has a dual role in vivo acting as both an energy source and a differentiating agent.

This possible dual role of butyrate is of particular interest because of the possible prophylactic value of dietary fibre in decreasing the incidence of colonic cancer. When fibre is metabolised by the colonic microflora, the major metabolite is butyrate. ${ }^{6}$ It might therefore be postulated that a major role of dietary fibre is to raise levels of colonic butyrate thus increasing the differentiation pressure in colonic enterocytes. This theory has some indirect support from recent findings that butyrate concentrations are lower in the sigmoid and descending colon ${ }^{6}$ (and $M$ Lawson personal communication) the region where the incidence of colon cancer is highest.

We thank Miss Tina Taranto, Ms Jenny Jones, Ms Joy Melny and Mr Chris Lloyd for their expert technical assistance. We also wish to thank Mr L Wilson for his assistance with the scanning electron microscopy studies. We would also like to thank $\mathrm{Mr}$ D M A Francis, Department of Surgery, University of Melbourne, for providing the clinical details of the patient. Part of this work was funded by grants to Dr G P Young from the Anti-Cancer Council of Victoria and the McGauran Trust.

\section{References}

1 Whitehead RH, Macrae FA, St John DJB, Ma J. A colon cancer cell line (LIM1215) derived from a patient with inherited nonpolyposis colorectal cancer. $J$ Natl Cancer Inst 1985; 74: 759-65.

2 Kim YS, Tsao D, Siddiqui B, Whitehead JS, et al. Effects of sodium butyrate and dimethylsulfoxide on biochemical properties of human colon cancer cells. Cancer 1980; 45: 1183-92.

3 Leavitt J, Barrett JC, Crawford BD, Ts'ao POP. Butyric acid suppression of the in vitro neoplastic state of Syrian hamster cells. Nature 1978; 271: 262-5.

5 Prasad KN, Sinha PK. Effect of sodium butyrate on mammalian cells in culture: a review. In Vitro 1976; 12: 125-31.

6 Cummings JH. Short chain fatty acids in the human colon. Gut 1981; 22: 763-79. 
7 Roediger WEW. Utilization of nutrients by isolated epithelial cells of the rat colon. Gastroenterology 1982: 83: 424-9.

8 Whitehead RH, Bertoncello I. Webber LM, Pedersen JS. A new human breast carcinoma cell line (PMC42) with stem cell characteristics. I. Morphologic characterization. J Natl Cancer Inst 1983: 70: 649-61.

9 Young GP. Rose IS, Cropper S. Seetharam S. Alpers DH. Hepatic clearance of rat plasma intestinal alkaline phosphatase. Am J Physiol 1984: 247: G419-426.

10 Bradford M. A rapid and sensitive method for the quantitation of microgram quantities of protein utilizing the principle of protein-dye binding. Anal Biochem 1976; 72: $248-54$.

11 Nagatsu T, Hino M. Fuyamada H, et al. New chromogenic substrates for $x$-prolyl-dipeptidyl-aminopeptidase. Anal Biochem 1976; 74: 466-76.

12 Bancroft JD. Enzyme histochemistry. In: Bancroft JD, Stevens A, eds. Theory and practice of histological techniques. Edinburgh: Churchill Livingstone, 1982: 379-405.

13 Ma J, De Boer WG, Nayman J. Intestinal mucinous substances in gastric intestinal metaplasia and carcinoma studied by immunofluorescence. Cancer 1982; 49: $1664-7$.

14 Hauri H-P, Sterchi EE, Binez D, Fransen JAM, Marxer A. Expression and intracellular transport of microvillus membrane hydrolasis in human intestinal epithelial cells. J Cell Biol. 1985; 101: 838-51.

15 Leder A, Leder P. Butyric acid, a potent inducer of erythroid differentiation in cultured erythroleukemia cells. Cell 1975; 5: 319-22.

16 Kruh J. Effects of sodium butyrate, a new pharmacological agent, on cells in culture. Mol Cell Biochem 1982: 42: $65-82$.

17 Friend C, Scher WW, Holland JG, Sato T. Hemoglobin synthesis in murine virus-induced leukemia cells in vitro: stimulation of erythroid differentiation by dimethylsulfoxide. Proc Natl Acad Sci USA 1971; 68: 378-82.

18 Reuben RC, Rifkind RA, Marks P. Chemically in- duced murine erythroleukemic differentiation. Biochim Biophys Acta 1980; 605: 325-46.

19 Riggs MG. Whittaker RG, Neumann JR. Ingram VM. n-Butyrate causes histone modifications in HeLa and Friend erythroleukaemia cells. Nature 1977; 268: 462-4.

20 Collins SJ, Ruscetti FW, Gallagher RE, Gallo RC. Terminal differentiation of human promyelocytic leukemia cells induced by dimethyl sulphoxide and other polar compounds. Proc Natl Acad Sci USA 1978; 75: $2458-62$.

21 Kyritsis A. Joseph G. Chader GJ. Effects of butyrate, retinol and retinoic acid on human Y-79 retinoblastoma cells growing in monolayer culture. $J$ Natl Cancer Inst 1980: 73: 649-54.

22 Vidali G, Boffa LC. Bradbury EM, Allfrey VG. Butryate suppression of histone deacylation leads to accumulations of multiacetylated forms of histones $\mathrm{H3}$ and $\mathrm{H} 4$ and increased DNase 1 sensitivity of the associated DNA sequences. Proc Nall Acad Sci USA 1978; 75: 2239-43.

23 Scaly L. Chalkley R. Effect of sodium butyrate on histone modification. (ell 1978; 14: 115-21.

24 Tsao D, Morita A, Bella A, Luu P, Kim YS. Differentiatial effects of sodium butyrate, dimethyl sulfoxide and retinoic acid on membrane-associated antigen, enzymes and glycoproteins of human rectal adenocarcinoma cells. Cancer Res 1982; 42: 1052-8.

25 Shi ZR. Tsao D, Kim YS. Subcellular distribution, synthesis and release of carcinoembryonic antigen in cultured human colon adenocarcinoma cell lines. Cancer Re; 1983; 43: 4045-9.

26 Tsao D. Shi Z. Wong A. Kim YS. Effect of sodium butyrate on carcinoembryonic antigen production by human colonic adenocarcinoma cells in culture. Cancer Res 1983; 43: 1217-22.

27 Chung YS, Song IS. Erickson RH. Sleisenger MH. Kim YS. Effect of growth and sodium butyrate on brush border membrane-associated hydrolases in human colorectal cancer cell lines. Cancer Res 1985; 45: 2976-82. 